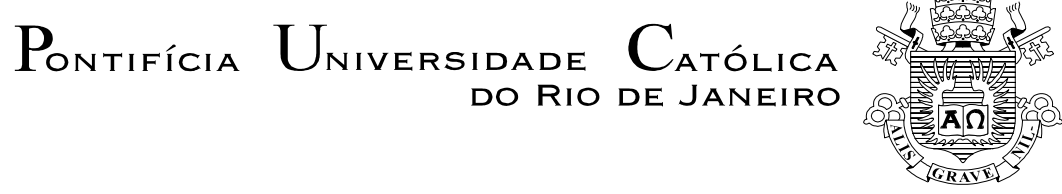

Sonia Maria de Souza Rosas

Entrevistas com o assistente social identidade, doença e estigma em uma enfermaria de adolescentes

Tese de doutorado

Tese apresentada ao Programa de Pósgraduação em Letras do Departamento de Letras da Puc-Rio como parte dos requisitos parciais para obtenção do título de Doutor em Letras.

Orientadora: Professora Doutora Liliana Cabral Bastos 


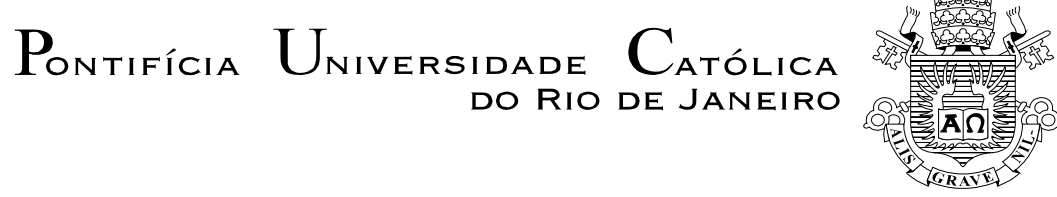

Sonia Maria de Souza Rosas

\title{
Entrevistas com o assistente social - identidade, doença e estigma em uma enfermaria de adolescentes
}

Tese apresentada como requisito parcial para obtenção do grau de Doutor pelo Programa de Pós-graduação em Letras do Departamento de Letras do Centro de Teologia e Ciências Humanas da PUC-Rio. Aprovada pela Comissão Examinadora abaixo assinada.

\author{
Profa. Liliana Cabral Bastos \\ Orientadora \\ Depto. de Letras - PUC-Rio
}

Profa. Branca Falabella Fabrício

Faculdade de Letras Anglo-Germânicas - UFRJ

Suely Ferreira Deslandes

IFF/FIOCRUZ

\section{Maria Cláudia Coelho}

UERJ

Profa. Maria das Graças Dias Pereira Depto. de Letras - PUC-Rio

Profa. Clarissa Rollin Pinheiro Bastos

Depto. de Letras - PUC-Rio (Suplente)

Profa. Sonia Bittencourt Silveira

Depto. de Letras - UFJF (Suplente)

Prof. Paulo Fernando Carneiro de Andrade Coordenador Setorial do Centro de Teologia e Ciências Humanas - PUC-Rio

Rio de Janeiro, 17 de março de 2006 
Todos os direitos reservados. É proibida a reprodução total ou parcial do trabalho sem autorização da universidade, da autora e da orientadora.

\section{Sonia Maria de Souza Rosas}

Graduou-se em Letras na Fahupe (Faculdade de Humanidades Pedro II) em 1989. Pós-graduou-se em Lingüística Aplicada na UERJ em 1990. Mestre em Língua Portuguesa pela PUC-Rio em 1996. Participou de diversos congressos na área de lingüística. É membro integrante da equipe de Alfabetização da DGED/DEF da SME. Atuou como professora em diferentes universidades, como a PUC-Rio, UERJ, Gama Filho, Castelo Branco e UFSM.

Ficha catalográfica

Rosas, Sonia Maria de Souza
Entrevistas com o assistente social: identidade,
doença e estigma em uma enfermaria de
adolescentes / Sonia Maria de Souza Rosas ;
orientadora: Liliana Cabral Bastos. - Rio de Janeiro :
PUC, Departamento de Letras, 2006.
222 f. ; $30 \mathrm{~cm}$
Tese (doutorado) - Pontifícia Universidade
Católica do Rio de Janeiro, Departamento de Letras.
Inclui referências bibliográficas.
1. Letras - Teses. 2. Identidade. 3.
Posicionamento. 4. Alinhamento. 5. Narrativa. 6.
Estigma. 7. Enquadre. I. Pontifícia Universidade
Católica do Rio de Janeiro. Departamento de Letras.
II. Título.

CDD: 400 
Para minha filha Rebeca, que foi gerada junto com o projeto desse trabalho e me deu a incomparável satisfação ao me dar o título de mãe. 


\section{Agradecimentos}

À minha orientadora Professora Liliana Cabral Bastos pelo estímulo e parceria para a realização deste trabalho.

Ao CNPq e à PUC-Rio, pelos auxílios concedidos, sem os quais este trabalho não poderia ter sido realizado.

À Secretaria Municipal de Educação do Rio de Janeiro pela licença concedida durante todo o período do doutorado.

À direção do NESA por ter permitido a gravação das entrevistas.

Aos assistentes sociais, mães e pacientes que participaram das entrevistas.

À minha amiga Jonê Carla Baião que me acompanha de outras caminhadas e continua, com sua amizade e apoio, me ajudando a crescer.

Aos colegas do Grupo de Pesquisa Narrativa, Identidade e Trabalho pelo companheirismo, incentivo e pelas importantes colaborações feitas ao meu trabalho.

À minha mãe e minha sogra pela atenção à minha filha quando eu precisava me ausentar.

Ao meu amado esposo e parceiro de sempre.

Ao pastor e professor Isaías, pelas importantes contribuições e palavras de apoio. 
Aos meus colegas da PUC-Rio, pelas palavras de incentivo.

Aos professores que participaram da Comissão examinadora.

A todos os professores e funcionários do Departamento pelos ensinamentos e pela ajuda.

À Coordenação de Pós-Graduação e à Direção do Departamento de Letras.

A Sonia Rosa, minha mais nobre homônima, pela amizade, companheirismo, apoio e incentivo, durante toda esta jornada.

A todos os amigos e familiares que de uma forma ou de outra me estimularam ou me ajudaram. 


\section{Resumo}

Rosas, Sonia Maria de Souza; Bastos, Liliana Cabral. Entrevistas com o assistente social - identidade, doença e estigma em uma enfermaria de adolescentes. Rio de Janeiro, 2006. 222p. Tese de Doutorado Departamento de Letras, Pontifícia Universidade Católica do Rio de Janeiro.

A tese "Entrevistas com o assistente social - identidade, doença e estigma em uma enfermaria de adolescentes" investiga a construção de identidades de três adolescentes atendidos em um hospital público do Rio de Janeiro. Foram analisadas entrevistas de assistentes sociais com esses adolescentes e suas mães. Buscou-se observar como os sentidos da doença, ou de suas conseqüências, relacionam-se com as construções identitárias em situação de interação face-a-face, a partir de categorias como posicionamento, alinhamento, enquadres interativos, pistas de contextualização e narrativa. Ancorando-se na Sociolingüística Interacional, a análise assume uma perspectiva interdisciplinar, com a utilização de conceitos de outras áreas das Ciências Humanas e Sociais, tais como a Psicologia Social e Estudos Culturais Foi observado como, em suas falas, os pacientes-adolescentes e suas mães lidam com as diferenças físicas e sociais a partir das enfermidades que esses adolescentes têm ou tiveram. Observamos também como, tendo em foco tais marcas, diferentes identidades dos adolescentes se constroem, em função de diferentes relações com o estigma. Assim, identidades e sentidos das doenças se constroem localmente, durante e pela situação de interação com os assistentes sociais. Acreditamos que a análise da construção do estigma, ao se valer das noções de posicionamento e alinhamento, contribui para os estudos do discurso, que investigam a relação entre linguagem, identidade e sociedade. Por outro lado, ao focalizar a questão do estigma, acreditamos também estar contribuindo para as discussões sobre o atendimento a adolescentes oriundos de classes populares, com dificuldades para integrar-se na sociedade, em conseqüência das marcas deixadas por alguma enfermidade.

\section{Palavras-chave:}

Identidade; posicionamento; alinhamento; narrativa; estigma; enquadre. 


\section{Abstract}

Rosas, Sonia Maria de Souza; Bastos, Liliana Cabral (Advisor). Interviews with social workers - identity, disease and stigma in an adolescent ward. Rio de Janeiro, 2006. 222p. PhD Dissertation Departamento de Letras, Pontifícia Universidade Católica do Rio de Janeiro.

The dissertation "Interviews with social workers - identity, disease and stigma in an adolescent ward" investigates the construction of identities of three adolescents assisted at a public hospital in Rio de Janeiro. Through the analysis of social workers interviews with these adolescents, and their mothers, we aimed at observing how the disease and its consequences were linked to the identities constructed in a situation of face-to-face interaction. The categories used in the analysis were positioning, alignment, interactive frame, contextualization cues and narrative. From an Interactional Socilolinguistics perspective, we assume an interdisciplinary view, using concepts from other areas of the Humanities and Social Sciences, such as Social Psychology and Cultural Studies. The investigation reveals how adolescent-patients, and their mothers, deal with physical and social differences caused by diseases. The research findings point to the construction of different identities for those adolescents through their discourses, and their mothers', according to the relation they had with the stigma. It was also observed how the meaning of the disease was built during the interaction situation with the social workers. The purpose of relating the construction of the stigma to participants' positionings and alignments in the interaction made possible to observe how the adolescents and their families deal with the social construction of the disease. This kind of analysis may contribute to discourse studies which investigate the relation between language, identity and society. The study can also contribute to the discussion of services provided to working class adolescents, who have difficulties to integrate in social life, due to health problems.

\section{Keywords:}

Identity; positioning; alignment; narrative; stigma; frame. 


\section{Sumário}

1 Introdução 15

1.1 A perspectiva do estudo 15

1.2 O tema e questões de pesquisa 18

1.3 Os objetivos $\quad 20$

1.4 Justificativa e relevância da pesquisa 21

2 Pressupostos teóricos $\quad 24$

2.1 Introdução 24

2.2 Sociolingüística Interacional 25

2.2.1 Pistas de Contextualização 26

2.2.2 Enquadres 28

2.2.3 Alinhamentos 31

2.3 Posicionamentos 33

2.4 Alinhamento/Posicionamento 36

2.5 Identidade $\quad 39$

2.6 Estigma 43

2.7 Narrativa $\quad 48$

2.8 Contexto institucional - saúde 52

3 Aspectos metodológicos e contexto de pesquisa 54

3.1 O contexto hospitalar 56

3.2 Os participantes $\quad 57$

3.2.1 A adolescência 59

3.3 A situação de entrevista 61

3.3.1 A abertura - iniciando a cooperação 65

$\begin{array}{ll}3.3 .2 \text { mantendo a cooperação } & 67\end{array}$

4 O paciente fala de sua doença - lidando com o estigma 69

4.1 Introdução $\quad 69$

4.2 A doença $\quad 70$

4.2.1 A doença de Priscila 70

$\begin{array}{ll}\text { 4.2.2 A doença de Fernanda } & 79\end{array}$ 
4.3 A construção do outro nas entrevistas com os pacientes 87

4.4 Considerações sobre a análise das entrevistas com os 92 pacientes

5 As mães falam de seus filhos: doença, escola e trabalho 93

5.1 Introdução 93

5.2 O relatório do responsável $\quad 94$

5.2.1 Neide fala de Fernanda $\quad 94$

5.2.2 Francisca fala de Priscila 98

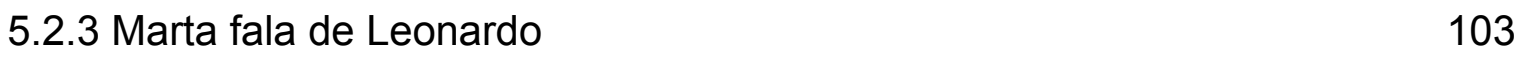

5.3 A relação assistente social / mãe e a construção de identidade 108 dos pacientes

5.3.1 Os direitos dos adolescentes 108

5.3.2 A cobrança 112

5.4 As idéias preconcebidas $\quad 120$

5.5 Considerações sobre a análise das entrevistas com as mães 124 dos pacientes

6 Mães e filhos: diferentes visões da doença 128

6.1 A doença de Fernanda $\quad 129$

6.2 A doença de Priscila: O desejo de avançar $X O$ fim de uma vida 136

6.3 A doença de Leonardo: Nomeando a doença 141

6.4 Considerações sobre as falas de mães e filhos sobre a doença 148

7 Considerações Finais 150

7.1 Interação e Estigma $\quad 151$

7.1.1 A identidade de Priscila 154

7.1.2 A identidade de Fernanda 156

7.1.3 A identidade de Leonardo 159

7.2 Identidade, Estigma e Estereótipos $\quad 161$

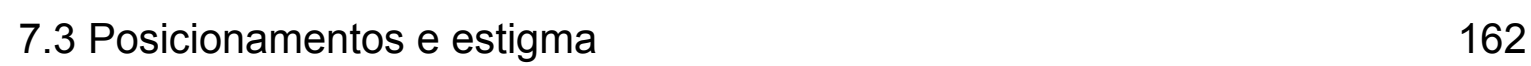


8 Referências Bibliográficas

9 Anexos 


\section{Lista de figuras}

Figura 1: Organização das entrevistas $\quad 64$

Figura 2: Grau de Estigmatização de Fernanda 125

Figura 3: Grau de Estigmatização de Priscila $\quad 126$

Figura 4: Formulações da pergunta da assistente social 133 
CONVENÇÕES DE TRANSCRIÇÃO

\begin{tabular}{|c|c|}
\hline Símbolos & Descrição \\
\hline (.) & $\begin{array}{l}\text { Micropausa de menos de dois décimos de } \\
\text { segundo, audível porém não cronometrável. }\end{array}$ \\
\hline$(1.5)$ & $\begin{array}{l}\text { Duração da pausa acima de um segundo } \\
\text { durante a fala, medida com o cronômetro }\end{array}$ \\
\hline$\cdot$ & $\begin{array}{l}\text { Descida de entonação, podendo ou não } \\
\text { coincidir com o final de enunciado. }\end{array}$ \\
\hline$?$ & Subida rápida sinalizando uma interrogação \\
\hline , & Descida leve, sinalizando que mais fala virá \\
\hline- & Não é enunciado o final projetado da palavra \\
\hline$:$ & Alongamento da vogal \\
\hline$::$ ou $:::$ & Duração mais longa do alongamento da vogal \\
\hline MAIÚSCULA & Ênfase ou acento forte \\
\hline Repetições & Reduplicação de letra ou sílaba \\
\hline ((comentário do analista $))$ & Informações extralingüísticas importantes \\
\hline ( ) & $\begin{array}{l}\text { Transcrição impossível. A repetição do } \\
\text { símbolo indica tentativa de discernimento da } \\
\text { quantidade de palavras pronunciadas. }\end{array}$ \\
\hline$/ \ldots 1$ & $\begin{array}{l}\text { Indicação de transcrição parcial ou de } \\
\text { eliminação }\end{array}$ \\
\hline[ & $\begin{array}{l}\text { Ponto de concomitância - sobreposições de } \\
\text { vozes } \\
\text { (quando a concomitância de vozes se dá } \\
\text { apenas em um dado ponto, com apenas um } \\
\text { dos falantes dando continuidade à fala) }\end{array}$ \\
\hline [ ] & $\begin{array}{l}\text { Indicação de abertura e fechamento do ponto } \\
\text { da sobreposição, com marcação nos } \\
\text { segmentos sobrepostos - sobreposições } \\
\text { localizadas }\end{array}$ \\
\hline$=$ & $\begin{array}{l}\text { Ausência de pausa entre: 1) a fala de um } \\
\text { mesmo falante; 2) dois falantes distintos. }\end{array}$ \\
\hline$>$ palavra $<$ & Fala mais rápida \\
\hline$<$ palavra $>$ & Fala mais devagar \\
\hline$?$ & $\begin{array}{l}\text { Subida de entonação mais forte que a vírgula } \\
\text { (sinal de continuação), porém menos forte } \\
\text { que o ponto de interrogação (subida de } \\
\text { entonação). }\end{array}$ \\
\hline- & $\begin{array}{l}\text { Oclusão glotal (corte na fala ou auto- } \\
\text { interrupção) }\end{array}$ \\
\hline sublinhado & Acento ou ênfase no volume ou na altura. \\
\hline o & $\begin{array}{l}\text { A fala seguinte é marcadamente mais suave } \\
\text { ou devagar. }\end{array}$ \\
\hline$\uparrow$ & $\begin{array}{l}\text { Subida acentuada na entonação, mais forte do } \\
\text { que os dois pontos sublinhados. }\end{array}$ \\
\hline$\downarrow$ & $\begin{array}{l}\text { Descida acentuada na entonação, mais forte } \\
\text { do que dois pontos precedidos de sublinhado. }\end{array}$ \\
\hline$<$ palavras & Inicio acelerado do enunciado. \\
\hline
\end{tabular}




\begin{tabular}{|c|l|}
\hline hhh & $\begin{array}{l}\text { Expiração, risos, ou outros fenômenos } \\
\text { expiratórios não vocalizados. }\end{array}$ \\
\hline (h) & $\begin{array}{l}\text { Aspirações que ocorrem durante a cadeia da } \\
\text { fala, sendo isoladas desta forma de modo a } \\
\text { preservar a compreensão do enunciado. }\end{array}$ \\
\hline .hhh & Inspiração audível. \\
\hline "palavras" & Fala relatada. \\
\hline
\end{tabular}

